\title{
Tsounkranaglenea hefferni gen. et sp. nov. from Sabah, Malaysia (Coleoptera, Cerambycidae, Lamiinae: Saperdini)
}

\section{MEI-YING LIN ${ }^{1,2} \&$ SI-QIN GE ${ }^{2 *}$}

${ }^{1}$ Key Laboratory of Zoological Systematics and Evolution, Institute of Zoology, Chinese Academy of Sciences, Beichen West Road, Chaoyang Dist., Beijing, 100101, China.

${ }^{2}$ Engineering Research Center for Forest and Grassland Disaster Prevention and Reduction, Mianyang Normal University, 166 Mianxing West Road, Mianyang, Sichuan, 621000, China.

*Corresponding authors: Mei-Ying Lin (linmeiying2021@126.com); Si-Qin Ge (gesq@ioz.ac.cn) @ †ttps://orcid.org/0000-00015924-3400

\begin{abstract}
A new saperdine species belonging to a new genus, Tsounkranaglenea hefferni gen. et sp. nov., is described from Sabah, Malaysia. The new genus differs from other genera of the tribe Saperdini by the special male sternite VII modified into a rake-shape, with the apex of the ventral plate of the median lobe unusually emarginated.
\end{abstract}

Key words: New genus, Glenea, Glenea subaurata, Asia, taxonomy

\section{Introduction}

Breuning's $(1952,1954)$ worldwide revisional work on the Saperdini sensu lato (including Saperdini and Phytoeciini) included 77 genera. In the Catalogue of Palearctic Coleoptera (Löbl \& Smetana, 2010), the Saperdini and Phytoeciini were treated as two tribes, which we followed. Breuning $(1956,1958 \mathrm{a}, 1958 \mathrm{~b})$ reviewed the genus Glenea Newman, including 35 subgenera. A few genera were described or reinstated recently (Lin, Montreuil et al., 2009; Lin \& Tavakilian, 2012; Lin \& Holzschuh, 2013).

In this paper we describe a new genus and species of the tribe Saperdini sensu stricto, Tsounkranaglenea hefferni gen. et sp. nov., from Malaysia. It is similar to the genus Glenea Newman, 1842 but distinct by the peculiar sternite VII modified into a rake-shape and the apex of the ventral plate of the median lobe strangely emarginated.

\section{Materials and methods}

Photographs were taken with a Canon EOS 7D + Canon Macro $100 \mathrm{~mm}$, and the genitalia pictures were taken with a large depth-of-field 3D Digital Microscope (Keyence VHX-1000C). Photographs taken before 2015 (Figs. 15-16) were taken with a Sony T30.

\section{Specimens studied are deposited in the following collections:}

DHCO: Daniel Heffern Collection, Houston, Texas, USA;

IZCAS: Institute of Zoology, Chinese Academy of Sciences, Beijing, China;

MSNG: Museo Civico di Storia Naturale "G. Doria", Genova, Italy=Civic Museum of Natural History "G. Doria", Genoa, Italy;

NHMB: Naturhistorisches Museum (Museum Frey, Tutzing), Basel, Switzerland. 


\section{Results}

\section{Tsounkranaglenea gen. nov.}

Type species: Tsounkranaglenea hefferni sp. nov.

Diagnosis. It is mostly similar to Glenea by the lateral elytral carinae and truncate elytral apex, but can be distinguished by the elongated, bended and rake-shaped sternite VII. In fact, it differs from all other saperdine genera by the peculiar sternite VII in males. It also differs from Paraglenea Bates, 1866, Heteroglenea Gahan, 1897 (as defined in Lin, Montreuil et al, 2009) and Pareutetrapha Breuning, 1952 by the male claws of fore and hind legs simple instead of appendiculate or bifid and elytral apex truncated with sharp teeth instead of rounded or slightly truncated without sharp teeth. It also differs from Eumecocera Solsky, 1871 and Stenostola Dejean, 1835 by the elytra with lateral carinae and male claws of fore and hind legs simple instead of appendiculate or bifid. The combination of the following characters makes the new genus easily separable from other saperdine genera: prothorax without lateral tubercles, elytra with distinct lateral carinae, elytral apex truncated with long spines at outer angle, male claws with appendiculated tooth only in mesotarsi and female claws all simple, male sternite VII elongated and bended into a rake-shape.

Description. Small-sized (under $15 \mathrm{~mm}$ ). Head not broader than prothorax. Eyes deeply emarginate, not divided, lower eye lobe much vertically longer than (male) to subequal to (female) gena. Antennae longer than body, in male slightly longer than female, basal segments fringed with sparse setae, scape slightly expanded, second antennomere short, third antennomere always the longest, $4^{\text {th }}$ antennomere subequal to (female) to slightly longer than (male) scape, $4^{\text {th }}$ to $10^{\text {th }}$ slightly and gradually decreasing in length except $11^{\text {th }}$ being slightly longer than $10^{\text {th }}$. Prothorax cylindrical, without lateral tubercles, slightly narrowed around basal fifth. Elytra subparallel, truncated apically, with sharp teeth at both inner and outer angles, each with two distinct lateral carinae starting from the base and combined into apical outer tooth (Figs 1b, 11b). Procoxal cavity closed posteriorly (Fig. 11c), mesocoxal cavity open to mesepimeron, metanepisternum more than twice as wide anteriorly as posteriorly. Protarsi with first segment expanded in male (Fig. 1a), mesotibiae with an oblique groove with setae (Fig. 1b), hind femur reaching fifth abdominal segment, hind tarsi with first segment longer than the following two combined. Male claws: only anterior claws of mesotarsi appendiculate with small teeth (Figs. 4-5), posterior claws of mesotarsi without teeth, and claws of pro- and metatarsi simple. Females claws simple (Figs. 11a-11b). Male sternite VII elongated and bent into a rake-shape (Figs. 1-3), female sternite VII with a median groove (Fig. 11c).

Male terminalia. Apex of male tergite VIII emarginated (Figs. 6a-6c). Lateral lobes slender, with a strong tooth at ventral base (Fig. 8b); ringed part elbowed in the widest portion, converging; basal piece well-developed and bifurcated (Fig. 8c). Median lobe strongly curved, shorter than tegmen, dorsal plate shorter than ventral plate, apex of ventral plate emarginated (Fig. 9a). Median foramen not elongated. Endophallus with one band of supporting armature, 4 basal plate-like sclerites, and 3 rod-like sclerites. Ejaculatory duct single. Female terminalia: Setae of sternite VIII dense and long. Spermathecal capsule and gland positioned on apex of spermathecal duct. Spermathecal capsule strongly sclerotized, composed of an apical orb and a long stalk, spiculum ventrale longer than abdomen.

Etymology. The generic name is a combination of a Greek word tsounkrána ( $\tau \sigma 0 v \gamma \kappa \rho \alpha ́ v \alpha)$ and the genus name Glenea. The Greek word "tsounkrána" refers to the shape of sternite VII in male, which looks like a rake. Gender feminine.

Distribution. Malaysia.

Remarks. It is very similar to Glenea (Breuning, 1956; Breuning, 1958) by the elytral lateral carinae and truncated elytral apex, and the following characters are quite common in Glenea members: endophallus with 4 basal plate-like sclerites (Lin et al., 2009; Lin, Tavakilian et al., 2009a,b; Lin \& Lin, 2011; Lin \& Yang, 2011a, b; Lin et al., 2018), and 3 rod-like sclerites (Lin et al., 2009; Lin, Tavakilian et al., 2009a,b; Lin \& Lin, 2011; Lin \& Yang, 2011a, b; Lin \& Dai, 2012; Lin, 2013); spermathecal capsule strongly sclerotized, composed of an apical orb and a long stalk (Lin et al., 2009; Lin, Tavakilian et al., 2009b; Lin \& Yang, 2011a, b; Lin \& Dai, 2012). We separate it from Glenea based on the following reasons. : 1) Glenea is heterogeneous (Lin, Montreuil et al., 2009;), even though outer characters are very similar (Lin \& Tavakilian, 2012), this peculiar species does not match with any type species of the subgenera; 2) Though most of characters can be found in the previous Glenea members, and the 
peculiar male sternite might not be suitable for generic level, but with only one band of supporting armature and the emarginated apex of the ventral plate of the median lobe, this convinced the authors to make a new genus. Most members of Saperdini have zero or two bands of supporting armature, rounded to the pointed apex of the ventral plate of the median lobe (Lin et al., 2009; Lin, Tavakilian et al., 2009a, b; Lin \& Yang, 2011a, b; Lin \& Dai, 2012; Lin, 2013; Lin et al., 2018). 3) Although the sexual dimorphism (on pubescence markings) referred to the subgenus Glenea (Acutoglenea) Breuning, 1958, and the dark integument referred especially to G.(A.) versuta basaloides Breuning 1958, G.(A.) versuta maura Pascoe, 1867, it can not be included in the subgenus Acutoglenea because of the non-simple male claws and very different male terminalia (based on the first author's unpublished data). Besides, the type species Glenea (Acutoglenea) acuta (Fabricius, 1801) has a stouter female, with elytral length less than twice basal width, fourth antennomere much shorter than scape, which are very different from the new taxon herein described. 4) We have checked the subgenus Glenea (Lineatoglenea) Breuning, 1950, which is represented by a unique type species Glenea (Lineatoglenea) lineatopunctata Breuning, 1950 from Malaysian Borneo. There are no images available, and we did not have an opportunity to examine the type specimen which should be deposited in University of Malaysia, Sarawak (Breuning, 1950a). Based on the original description, it shares with the new taxon by antennae longer than body, similar antennomere ratio, pronotum and elytra, however it differs from the new taxon by the fifth male abdominal segment provided at the end with a short median longitudinal ridge. 5) We have checked the subgenus Glenea (Spiniglenea) Breuning, 1958, which is represented by a unique type species Glenea (Spiniglenea) spinosipennis Breuning, 1958 from Malaysian Borneo. It also has no images available, and we did not have an opportunity to examine the type specimen which should be deposited in University of Malaysia, Sarawak (Breuning, 1958b). Based on the original description, it is difficult to separated it from the new taxon on genus level, since it was based only on a female. However, it is surely not the same species. 6) We compared the new taxon with Glenea (Metaglenea) Breuning, 1956, which is represented by a species from Sumatra, and Glenea (Porphyrioglenea) Breuning, 1956, which is represented by a species from West Malaysia and Sabah, East Malaysia. They can be easily distinguished from the new taxon by the very close antennal tubercles, shorter and stouter antennae. Glenea (Pseudotanylecta) Breuning, 1956, Glenea (Subgrossoglenea) Breuning, 1956, Glenea (Tanylecta) Pascoe, 1866 also from Malaysia and Indonesia, can be separated by the close and protruding antennal tubercles. 7) Glenea (Poeciloglenea) Aurivillius, 1920, Glenea (Punctoglenea) Breuning, 1956, Glenea (Reginoglenea) Breuning, 1956, Glenea (Rubroglenea) Breuning, 1956, Glenea (Rufoglenea) Breuning, 1956, Glenea (Stiroglenea) Aurivillius, 1920, Glenea (Vanikoroglenea) Breuning, 1956, Glenea (Vittiglenea) Breuning, 1956, Glenea (Volumnia) Thomson, 1860 and all other subgenera have been studied by the first author, and none of them are suitable for the new taxon. 8) The new taxon differs from Glenea (Lobunguiglenea) Lin \& Tavakilian, 2014 by the male claws with only anterior claw of mesotarsus appendiculate with small lobe in inner side, instead of all claws appenciculated in outer sides, and genitalia with median lobe strongly curved, apex of ventral plate emarginated, instead of genitalia with median lobe slightly curved, apex of ventral plate pointed.

\section{Tsounkranaglenea hefferni sp. nov.}

(Figs. 1-14)

Type material. Holotype, male (Fig. 1), Malaysia, Sabah, Crocker Range, 2003-II-16, leg. local coll. (IZCAS). Paratypes: 1 male, Malaysia, Sabah, Mt. Trus Madi, 1500-2000m, 1998-III-11, leg. Affenddy (DHCO); 1 female, Malaysia, Sabah, Mt. Trus Madi, 1500-2000m, 1998-III/V, leg. local coll. (IZCAS); 1 female, Malaysia, Sabah, Crocker Range, 2010-III-18, local coll. (DHCO); 1 female, same data but 1998-III-19 (DHCO).

Other material (examined only by photographs). 1 male with length $11.5 \mathrm{~mm}$, no. S11.9-151. Nobuo Ohbayashi showed the first author a specimen from Malaysia with dorsal view and lateral view pictures in 2011, which was surely this species. It may be from Trus Madi, however, the owner Mr. Minoru Sawai could not be contacted during this research.

Description (based on two males and three females): Male: length: 11.0-11.5 mm, humeral width: 3.0-3.2 mm. Female: length: 11.0-14.0 mm, humeral width: 3.4-4.2 mm. Body black. Head black, with frons covered with dense grayish white to yellow pubescence (Figs. 2e, 11d), which extends as two short vittae to occiput; antennae black. Prothorax covered with dense brownish pubescence in dorsal view except a whitish pubescent spot at base for both sexes and a whitish spot in middle of apical part for female only (Figs. 11a, 12); with a longitudinal grayish 


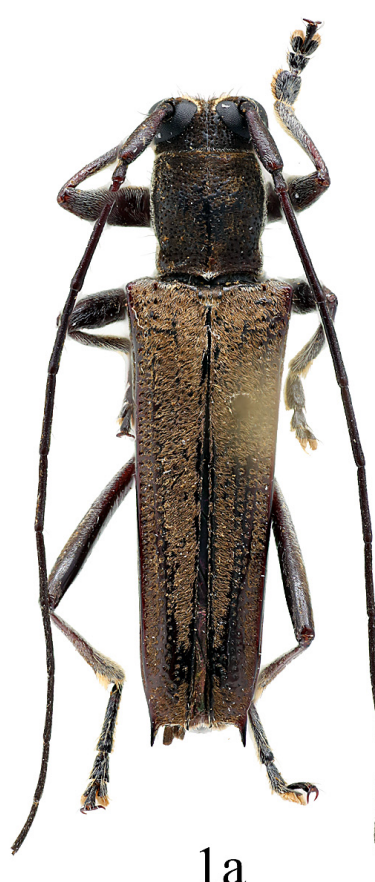

la
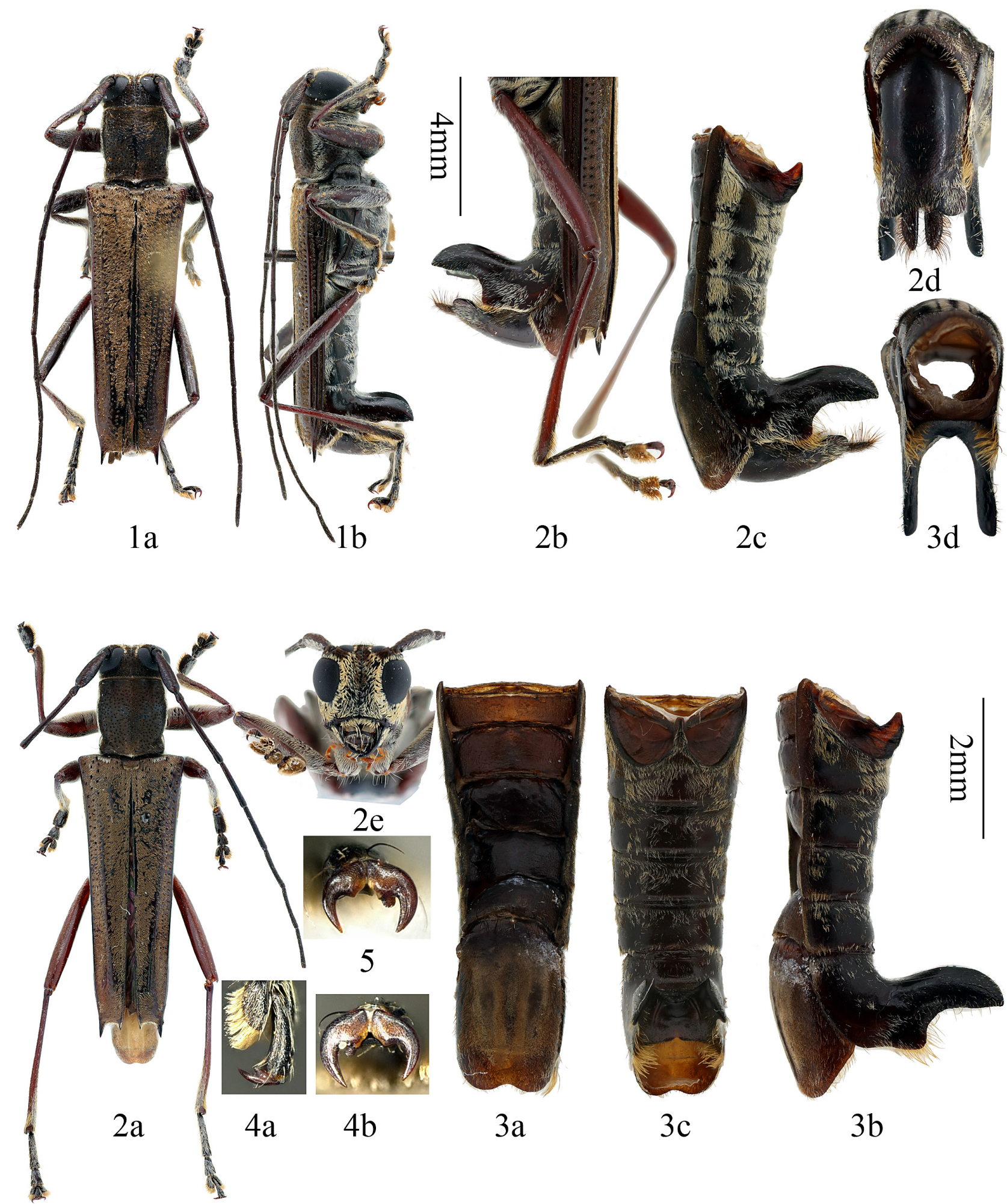

FIGURES 1-5. Tsounkranaglenea hefferni gen. et sp. nov. 1. Holotype, male. 2-5. Paratype, female. 2b-d, showing abdomen especially the $7^{\text {th }}$ and $8^{\text {th }}$ segment; 3, abdomen with genitalia removed; 4, claw of left middle tarsus; 5, claw of right middle tarsus. a, dorsal view; 4a, dorsa-lateral view; b, lateral view; 4b, back view; 2c, lateral view; 3c, ventral view; d, back view; e, frontal view. 1a, 1b, 2a: scale bar $4.0 \mathrm{~mm}$; 3a-3c: scale bar $2.0 \mathrm{~mm}$; others not to scale.

white to yellow pubescence in lateral view (Figs. 1b, 11b). Scutellum black, covered by brownish (basal part) and whitish (apical part) pubescence. Elytra black, covered by rather dense brownish pubescence, at basal fourth and along suture with some silver erect setae, basal setae much longer than others (Fig. 12), and with grayish white to 
yellow pubescence markings on each elytron as following: (for both sexes) a transverse vitta at base; a apical vitta; (for only female) a long line along second row of punctures (counting from lateral carina) from nearly base to apical tenth, normally with a subapical interruption; a lateral line along the puncture row near lateral carina from nearly base to middle (Fig. 11b); a short longitudinal vitta along suture just behind scutellum (Fig. 11a, sometimes missing, Fig. 12). Ventral surface black with grayish white pubescence except a long stouter line with interruptions caused by lacking pubescence (Figs. 1b, 11b). Legs reddish brown to dark brown, covered with grayish pubescence. Frons longer than broad, width less than (male) or subequal to (female) two eyes's combined width. Antennomere ratio: male, 25:5:36:28:27:26:25:24:22:20:21; female, 25:5:36:26:25:24:23:21:19:18:19. Prothorax longer than (male) to as long as (female) broad. Elytron truncated apically, with a short tooth at inner angle and a sharp and long tooth at outer angle. Hind femur reaching base of (female) or the bent part of (male) fifth abdominal segment, first hind tarsal segment longer than the following two segments combined. The sternite VII in male (Figs. 2b, 2c, 3b-d) strongly bent at base, the apical half reduced and transformed into two slender knife-shaped teeth (Figs. 3b-d), with long brown brush hairs on the outer side.

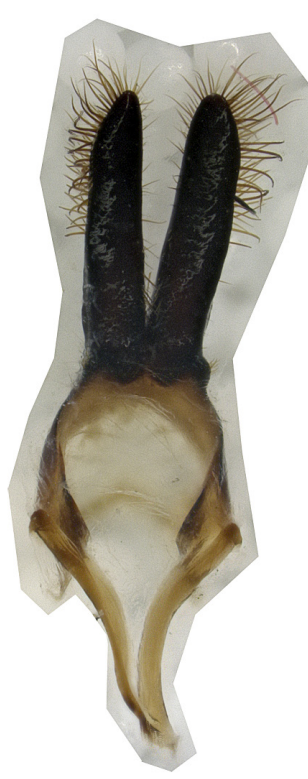

$8 \mathrm{a}$

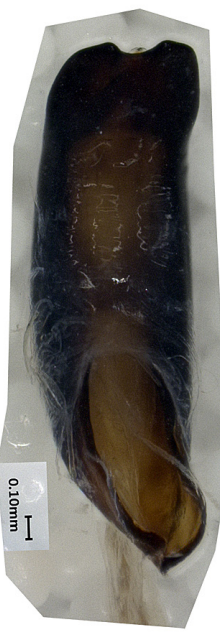

$9 \mathrm{a}$

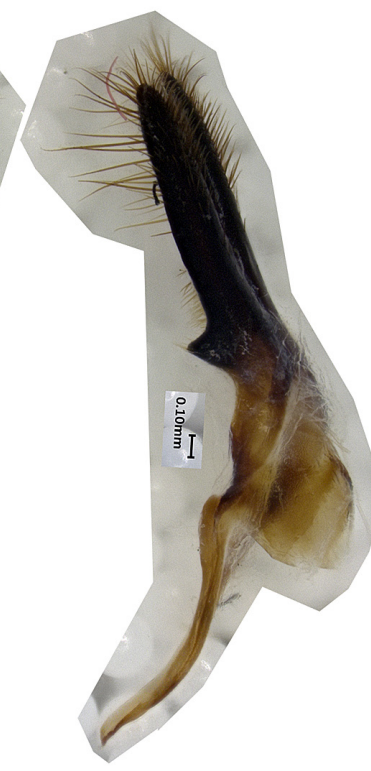

$8 b$

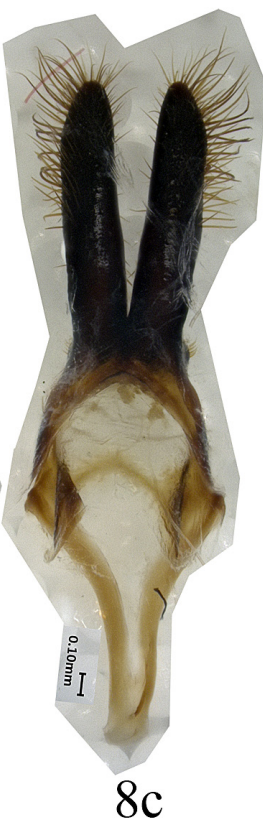

$8 \mathrm{c}$

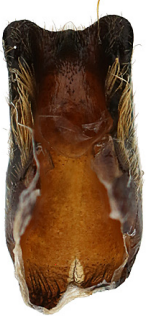

$6 \mathrm{a}$

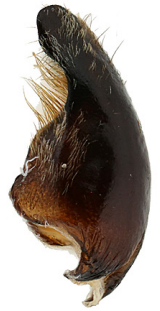

$6 b$

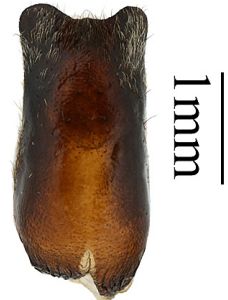

$6 \mathrm{c}$
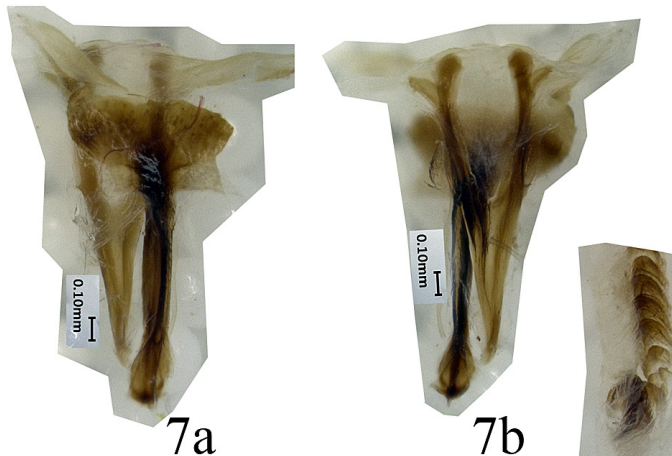

$7 \mathrm{~b}$

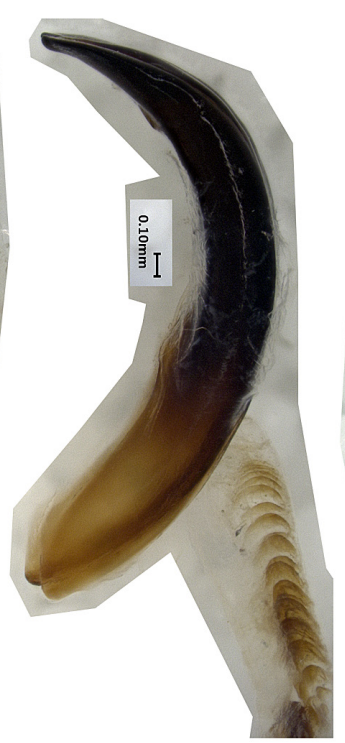

$9 d$

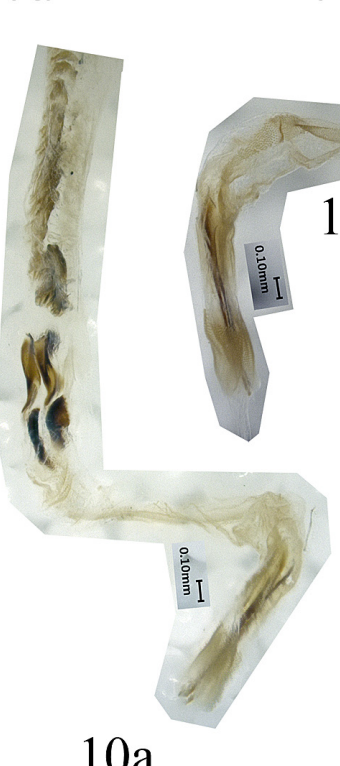

$10 \mathrm{a}$

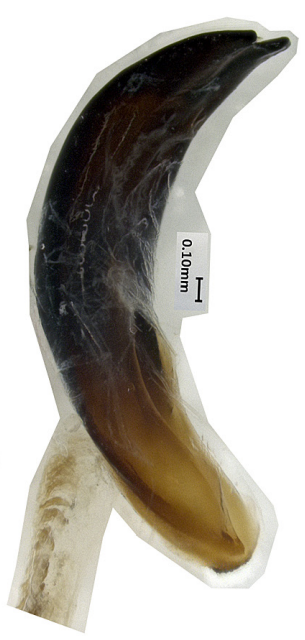

$9 \mathrm{~b}$
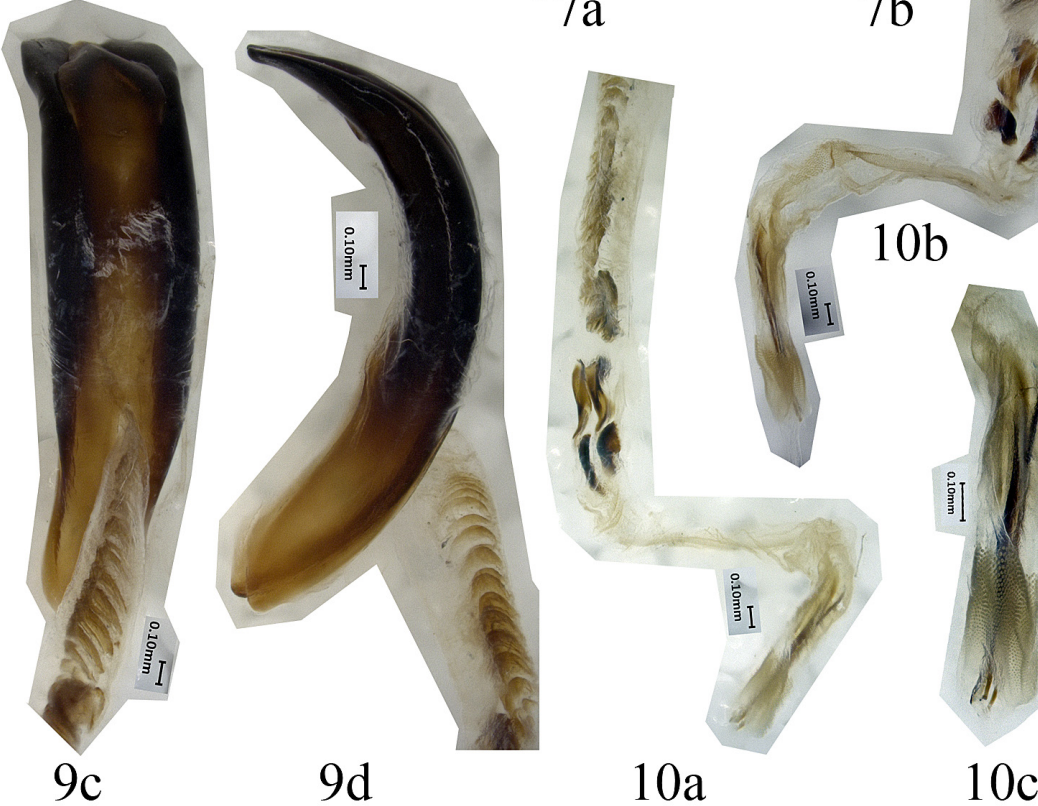

$10 b$

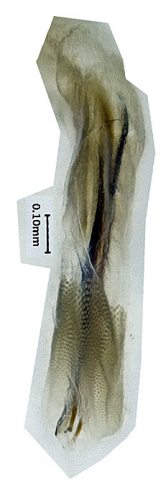

$10 \mathrm{c}$

FIGURES 6-10. Terminalia of Tsounkranaglenea hefferni gen. et sp. nov. 6, Tergite VIII; 7, sternites VIII \& IX; 8. Tegmen; 9 , Median lobe; 10, endophallus, showing a band of supporting armature, basal plate-like sclerites and rod-like sclerites. a, Ventral view; b, Lateral view, 7b, dorsal view; c, dorsal view; d, lateral view. 7-10, Scale bar $0.1 \mathrm{~mm}$; 6, scale bar $1.0 \mathrm{~mm}$. 

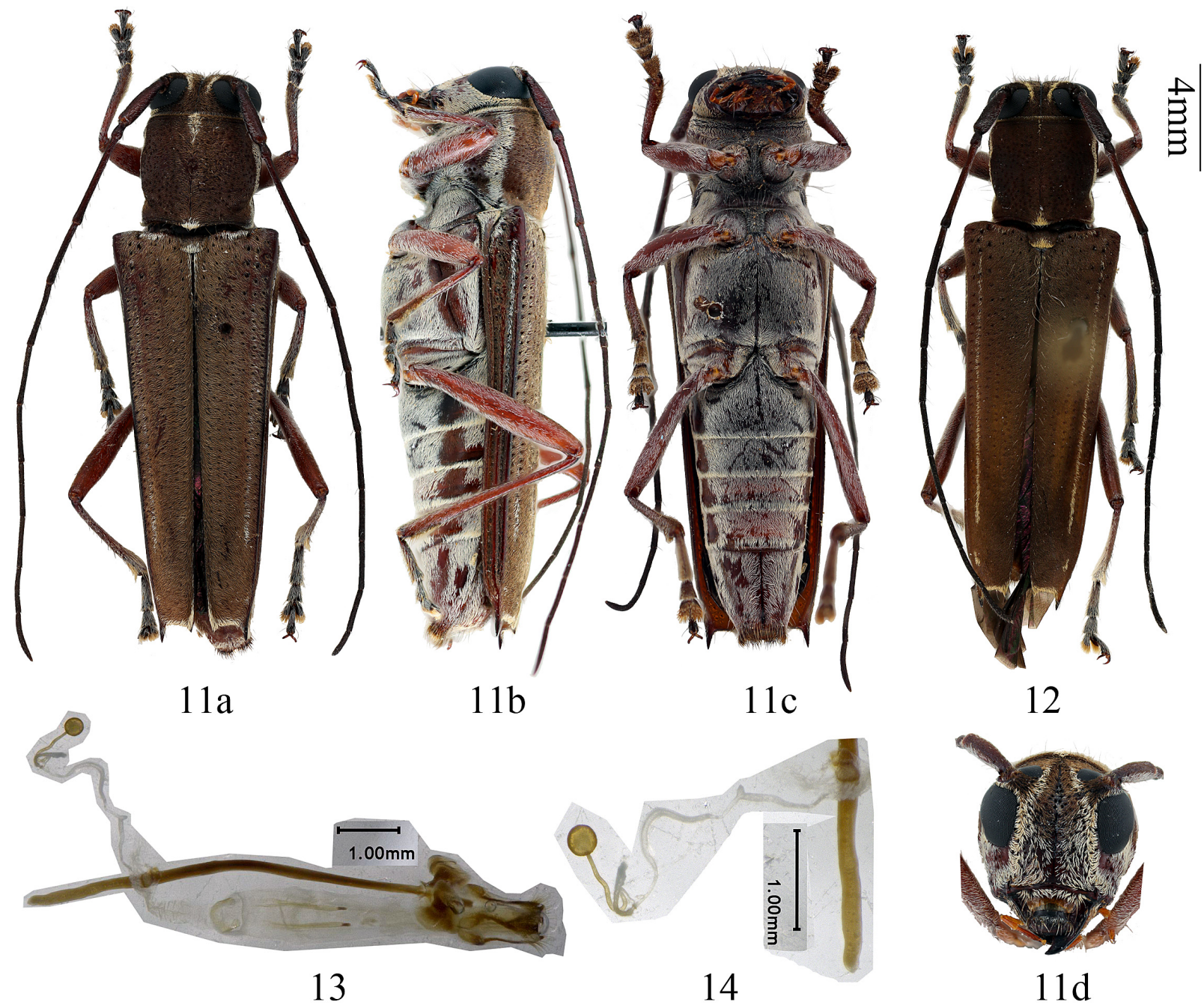

FIGURES 11-14. Females of Tsounkranaglenea hefferni gen. et sp. nov. 11, paratype, dissected; 12, paratype, just emerged, showing the erected setae along suture; a, dorsal view; b, lateral view; c, ventral view; d, frontal view. 13-14. Female genitalia. 11-12, scale bar $4.0 \mathrm{~mm}$; 13-14, scale bar $1.0 \mathrm{~mm}$.

Male terminalia (Figs. 6-10): Tegmen about $3.0 \mathrm{~mm}$ in length; lateral lobes slender (Figs. 8a, 8c), each about $1.2 \mathrm{~mm}$ long and $0.3 \mathrm{~mm}$ wide, provided with a thin setae, strongly protruding lobe at ventral base (Fig. $8 \mathrm{~b}$ ), apical half with medium long setae; ringed part elbowed in widest portion, converging; basal piece bifurcated apically (Figs. 8c); median lobe plus median struts strongly curved (Figs. 9b, 9d), shorter than tegmen; median struts more than one third and less than half of whole median lobe in length; dorsal plate slightly shorter than ventral plate; apex of ventral plate strongly emarginated, forming two lateral apical lobes (Figs. 9a, 9b); median foramen slightly elongated; internal sac about triple length of median lobe, with two pairs of basal plate-like sclerites (located behind apex of median struts), one band of distinct supporting armature, some barely separated plate-like sclerites between them, and three rod-like sclerites at the end (Figs. 10a-10c), rod-like sclerites about $1.0 \mathrm{~mm}$, much shorter than median lobe or tegmen. Tergite VIII (Figs. 6a-6c) longer than broad, strongly narrowed before apex (Fig. 6b), apex emarginated with two short ear-shaped lateral lobes, with dense and long brown setae along the narrowed part (Figs. 6a, 6b). Sternite VIII with spiculum relictum as Fig. 7b, sternite IX (spiculum gastrale) as Fig. 7a. Female genitalia (Figs. 13-14): spermathecal capsule composed of an apical orb and a long and strongly curved stalk, the stalk more than triple the length of the apical orb, curved twice at basal part (Fig. 14). Spiculum ventrale longer than abdomen. In our observation, spiculum ventrale measured $7.7 \mathrm{~mm}$ for an adult compared with abdomen which measured 5.7 $\mathrm{mm}$ in ventral view.

Etymology. The species is named after Mr. Daniel Heffern (Texas, USA), who offered the interesting material for this study and provided the first author some wonderful saperdine specimens from Malaysia for research. 


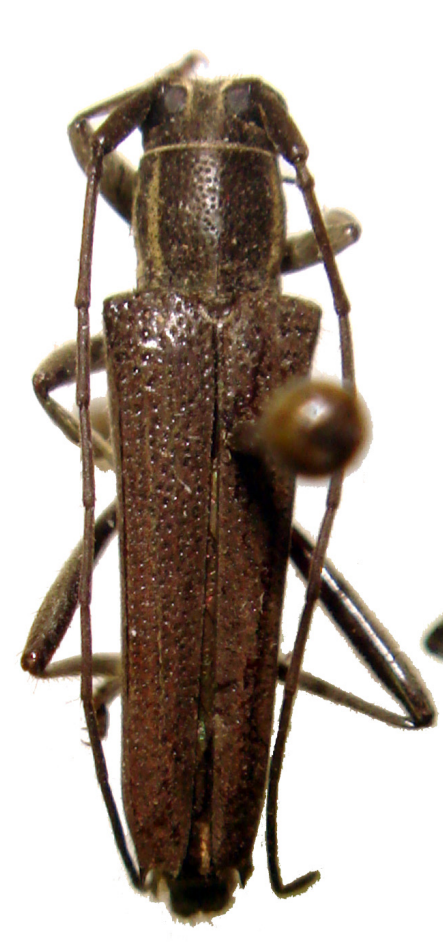

$15 a$

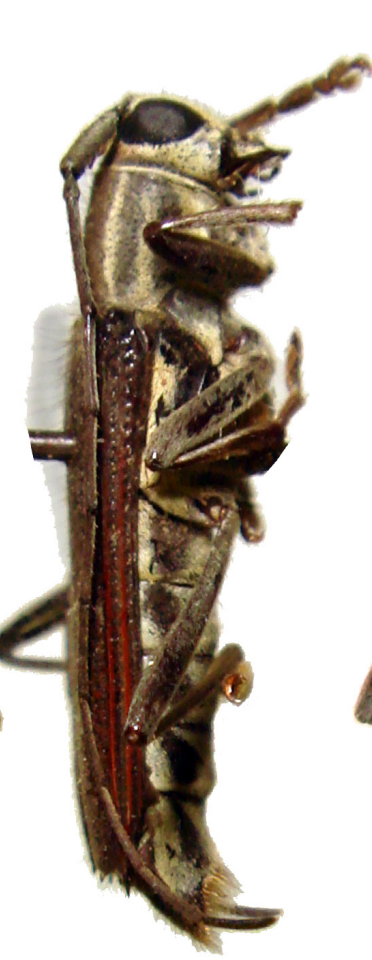

$15 b$

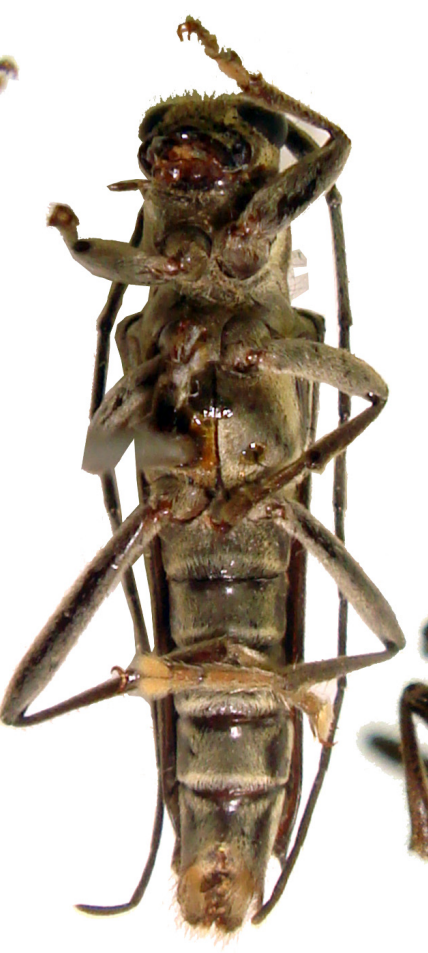

$15 \mathrm{c}$
荣

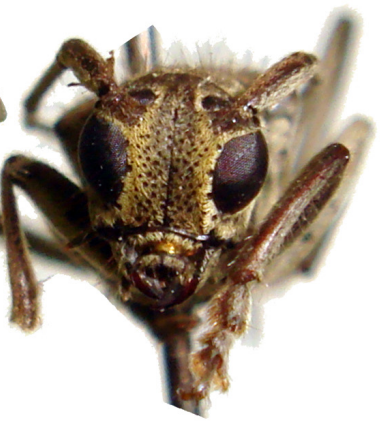

$15 d$

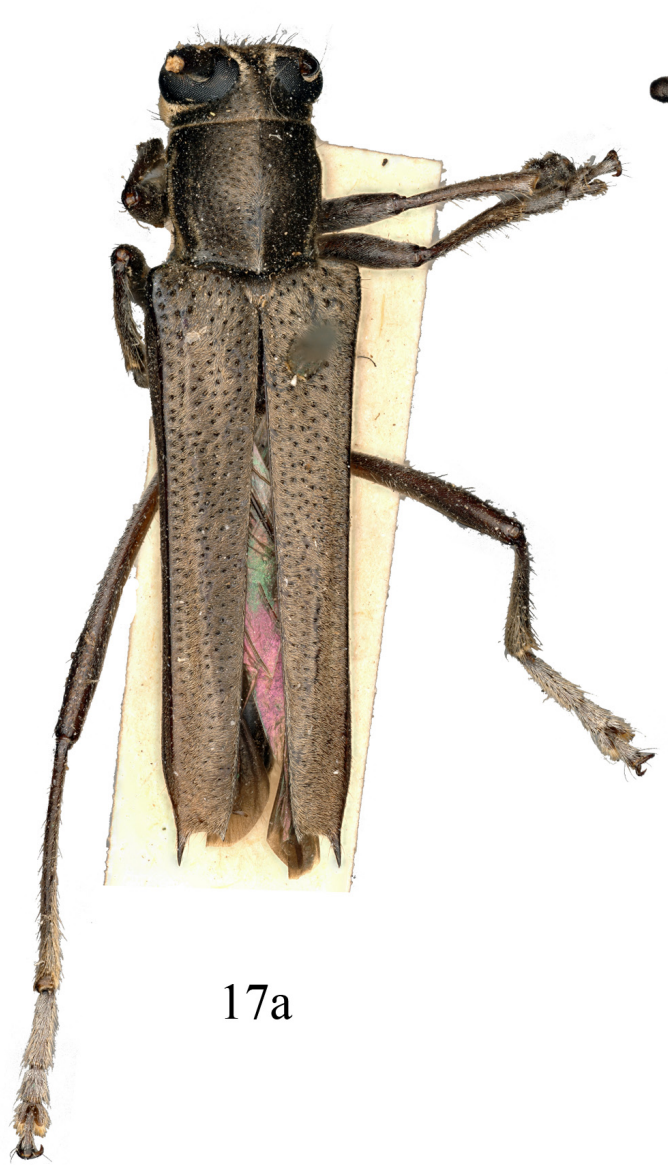

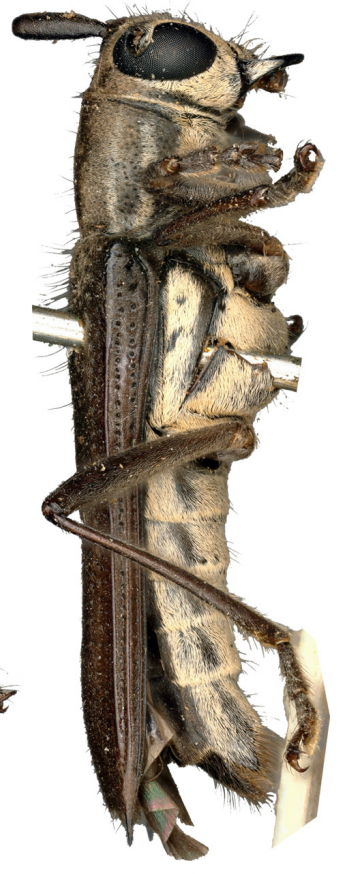

$17 b$

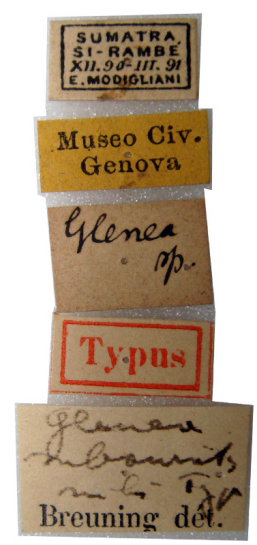

16

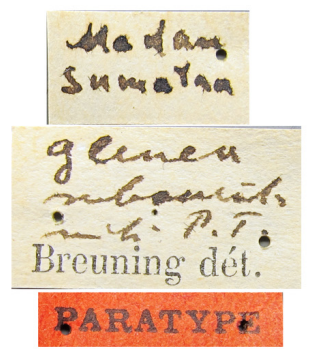

18

FIGURES 15-18. Glenea subaurata Breuning, 1950. 15-16, holotype, male; 17-18, nontype, male; a, dorsal view; b, lateral view; c, ventral view; d, frontal view. 16 \& 18, labels. 15 (except 15d) \& 17, scale bar $4.0 \mathrm{~mm}$; others not to scale. 
Diagnosis. This species resembles Glenea subaurata Breuning, 1950 at first glance by the similar shape and colour. The specific differences are easily defined by the male sternite VII. Without specimens for dissection, we can not conclude whether Glenea subaurata Breuning, 1950 should be moved to the new genus Tsounkranaglenea or not.

Remarks. Glenea subaurata Breuning, 1950 (Figs. 15-18) was described based on "Type un male de Sumatra: Si-Rambé, XII-1890-III-1891, leg. E. Modigliani”, with "Longuer $10 \mathrm{~mm}$, Largeur 2mm. 1/3". The holotype male (Figs. 15-16) is deposited in MSNG and had been examined by the first author in June, 2008. Another male specimen (Figs. 17-18) is deposited in NHMB, with a label written "PARATYPE". Though it has a Breuning's handwriting label "glenea / subaurata / mihi. P. T. / Breuning det.", it is not a paratype because the locality "Madam / Sumatra" and the individual specimen were not mentioned in the original paper (Breuning, 1950b). Here we confirmed that the identification is correct and it is a useful additional material for the specific definition of Glenea subaurata Breuning, 1950.

\section{Acknowledgements}

We are grateful to Mr. Daniel Heffern (Texas, USA) for providing the interesting Malaysian material, contacting staff at NHMB and improving the English language of the manuscript, to Fabro Penati (MSNG) for giving the first author access to the collection in June, 2008, to Christoph Germann (NHMB) for providing good quality pictures of a male Glenea subaurata Breuning, 1950. We thank Kui-Yan Zhang for assistance to take images with a large depth of field 3D Digital Microscope (Keyence VHX-1000C). We thank Nobuo Ohbayashi (Japan) for providing the Malaysian pictures during previous studies.

This research was supported by the National Natural Science Foundation of China NSFC programs 31472029 (Mei-Ying Lin) and J1210002, the China Scholarship Council (201704910195 to Mei-Ying Lin) and partly by a grant (Y229YX5105) from the Key Laboratory of the Zoological Systematics and Evolution of the Chinese Academy of Sciences.

\section{References}

Aurivillius, C. (1920) Neue oder wenig bekannte Coleoptera Longicornia. 17. Arkiv för Zoologi, 13 (9), 1-43 (=361-403), figs. 73-81. https://doi.org/10.5962/bhl.part.20147

Breuning, S. (1950a) Nouvelles formes de Lamiaires (Cerambycidae, Coleoptera). The Sarawak Museum Journal, 5 (2), 373388.

Breuning, S. (1950b) Nouveaux Lamiaires du Musée de Gênes (Coleoptera, Cerambycidae). Annali del Museo Civico di Storia Naturale Giacomo Doria, Genova, 64, 170-201.

Breuning, S. (1952) Revision einiger Gattungen aus der Gruppe der Saperdini Muls. (Col. Cerambycidae). Entomologischen Arbeiten aus dem Museum G. Frey, Tutzing bei München, 3 (1), 107-213, 3 pls.

Breuning, S. (1954) Revision von 35 Gattungen aus der Gruppe der Saperdini Muls. (Col. Cerambycidae). Entomologischen Arbeiten aus dem Museum G. Frey, Tutzing bei München, 5 (2), 401-567, 3 pls.

Breuning, S. (1956) Revision der Gattung Glenea Newman. Entomologische Arbeiten aus dem Museum G. Frey, Tutzing bei München, 7 (1), 1-199.

Breuning, S. (1958a) Revision der Gattung Glenea Newm. (Col. Ceramb.) (2. Fortsetzung). Entomologische Arbeiten aus dem Museum G. Frey, Tutzing bei München, 9 (1), 229-351, 4 figs.

Breuning, S. (1958b) Revision der Gattung Glenea Newm. (Col. Ceramb.) (3. Fortsetzung und Schluß). Entomologische Arbeiten aus dem Museum G. Frey, Tutzing bei München, 9 (3), 804-907.

Lin, M.-Y. (2013) Three new species of the genus Glenea Newman, 1942 from the Oriental Region (Coleoptera: Cerambycidae: Lamiinae: Saperdini). In: Lin, M.-Y. \& Chen, C.-C. (Eds.), In memory of Mr. Wenhsin Lin. Formosa Ecological Company, Taipei, pp. 107-116.

Lin, M.-Y. \& Dai, L. (2012) Description of a new species of the genus Glenea from Tibet, China (Coleoptera, Cerambycidae, Lamiinae, Saperdini). ZooKeys, 216, 5-11. https://doi.org/10.3897/zookeys.216.3360

Lin, M.-Y., Dar, M.A. \& Akbar, S.A. (2018) Taxonomy and distribution of Glenea beesoni Heller, 1926 (Coleoptera: Cerambycidae: Lamiinae: Saperdini) from Indian Himalayas. Oriental Insects, 52 (3), 221-228. https://doi.org/10.1080/003053 16.2017.1397565 
Lin, M.-Y. \& Holzschuh, C. (2013) Blamada rubripronota, a new genus and species of the tribe Saperdini (Coleoptera: Cerambycidae: Lamiinae) from Southeast Asia. Zootaxa, 3640 (1), 95-100.

https://doi.org/10.11646/zootaxa.3640.1.8

Lin, M.Y., Montreuil, O., Tavakilian, G. \& Yang, X.K. (2009) Reinstatement of the genus Heteroglenea Gahan, with four new combinations, four new synonyms and three new species (Coleoptera: Cerambycidae: Lamiinae: Saperdini). Zootaxa, 2137 (1), 1-22. https://doi.org/10.11646/zootaxa.2137.1.1

Lin, M.Y. \& Tavakilian, G. (2012) A New Genus Bifidunguiglenea gen. nov. Is Erected for the Species Glenea gestroi Gahan (Cerambycidae: Lamiinae: Saperdini). PLoS ONE, 7 (7), e40768, 1-5. https://doi.org/10.1371/journal.pone.0040768

Lin, M.-Y. \& Tavakilian, G. (2014) A strange new species Glenea judsoni sp. nov. from Taiwan, China (Coleoptera: Cerambycidae: Lamiinae: Saperdini). In: Hua, L.-Z. (Ed.), Feelings in China. Memorial works of Dr. J. L. Gressitt of the 100th Anniversary on his Birthday. Sun Yat-sen University, Guangzhou, pp. 161-167.

Lin, M.-Y., Tavakilian, G., Montreuil, O. \& Yang, X.-K. (2009a) Eight species of the genus Glenea Newman, 1842 from the Oriental Region, with description of three new species (Coleoptera: Cerambycidae: Lamiinae: Saperdini). Zootaxa, 2155 (1), 1-22. https://doi.org/10.11646/zootaxa.2155.1.1

Lin, M.-Y., Tavakilian, G., Montreuil, O. \& Yang, X.-K. (2009b) A study on the indiana \& galathea species-group of the genus Glenea, with descriptions of four new species (Coleoptera: Cerambycidae: Lamiinae: Saperdini). Annales de la Société Entomologique de France, New Series, 45 (2), 157-176. https://doi.org/10.1080/00379271.2009.10697599

Lin, M.-Y. \& Yang, X.-K. (2011a) A new species Glenea shuteae sp. nov. from Yunnan, China: compared with Glenea decolorata Heller (Coleoptera, Cerambycidae, Lamiinae, Saperdini). Acta Zootaxonomica Sinica, 36 (1), 40-44.

Lin, M.-Y. \& Yang, X.-K. (2011b) Glenea coomani Pic, 1926 and its related species of South China with description of a new species. ZooKeys, 153, 57-71. https://doi.org/10.3897/zookeys.153.2106

Lin, M.-Y., Yang, X.-K. \& Lin, Y.-L. (2009) Taxonomic Notes on Glenea pseudoscalaris (Fairmaire, 1895) (Coleoptera, Cerambycidae, Lamiinae). Longicornists, Special Bulletin of the Japanese Society of Coleopterology, No. 7, 385-390.

Löbl, I. \& Smetana, A. (Eds.) (2010) Catalogue of Palaearctic Coleoptera. Vol. 6. Chrysomeloidae. Apollo Books, Stenstrup, 924 pp.

Pascoe, F.P. (1866) Catalogue of longicorn Coleoptera, collected in the Island of Penang by James Lamb, Esq. (Part I.). Proceedings of the Zoological Society of London, 1866, 222-267, pls. XXVI-XXVIII.

Thomson, J. (1860) Essai d'une classification de la famille des cérambycides et matériaux pour servir à une monographie de cette famille. chez l'auteur [James Thomson] et au bureau du trésorier de la Société entomologique de France, Paris, xvi + $128 \mathrm{pp}$. https://doi.org/10.5962/bhl.title.9206 